\title{
O discurso bolsonarista sobre o viés ideológico na pandemia da COVID-19
}

The bolsonarist discourse about ideological bias at COVID-19 pandemic

\author{
Eric Duarte Ferreira ${ }^{1}$ \\ Universidade Federal da Fronteira Sul - UFFS \\ ericletras@gmail.com \\ Ana Cristina Agnoletto ${ }^{2}$ \\ Universidade Federal da Fronteira Sul - UFFS \\ anacristinaagnoletto@yahoo.com.br \\ Maruana Kássia Tischer Seraglio ${ }^{3}$ \\ Universidade Federal da Fronteira Sul - UFFS \\ maruana.seraglio@estudante.uffs.edu.br
}

\begin{abstract}
RESUMO: Neste artigo, apresentamos uma análise do discurso político do governo Bolsonaro em relação à atuação da OMS no combate ao coronavírus. Para isso, seguimos pela esteira de conceitos-chave da Análise de Discurso de orientação franco-brasileira: ideologia, memória, formação discursiva e governamentalidade. O objetivo é examinar como se produzem os efeitos de sentido relacionados à composição da marca discursiva do "viés ideológico" em pronunciamentos do presidente e do ministro das relações exteriores durante a pandemia de COVID-19. Buscamos compreender como a discursividade antiglobalista se materializa nesses discursos, imprimindo ao "viés ideológico" sentidos que seriam filiados à esquerda do espectro político brasileiro, contra os quais os sujeitos governantes se opõem.
\end{abstract}

Palavras-chave: Governo Bolsonaro; Coronavírus; Viés ideológico; Antiglobalismo; Governamentalidade; Discurso Presidencial.

ABSTRACT: This article presents an analysis of President Bolsonaro's political discourse about WHO's action in combating the coronavirus. We followed the key concepts of Discourse Analysis with French-Brazilian orientation: ideology, memory, discursive formation and governmentality. The aim is to examine how the effects of meaning related to the composition of the discursive mark "ideological bias" are produced in the speech of the subject president during the pandemic of COVID-19. We seek to understand how the anti-globalist discursiveness materializes in the president's speech, giving the "ideological bias"

\footnotetext{
${ }^{1}$ Doutor em Linguística e Professor do Curso de Letras e do Programa de Pós-Graduação em Estudos Linguísticos da Universidade Federal da Fronteira Sul, campus Chapecó-SC. Pesquisador do Laboratório de Estudos do Discurso da UFFS, o FRONTEIRAS, e do Grupo de Pesquisa Lingua(gem), discurso e subjetividade (UFFS). Coordenou, junto com o prof. Dr. Atilio Butturi Junior, a coletânea Análises no Campo do Discurso: Debates Interdisciplinares, publicado em 2017 pela Editora Mercado de Letras.

${ }^{2}$ Mestra em Estudos Linguísticos pela Universidade Federal da Fronteira Sul (UFFS), campus Chapecó-SC. Exbolsista Fapesc. Professora de Língua Portuguesa e Língua Inglesa da Escola de Educação Básica Bom Pastor, do município de Chapecó.

${ }^{3}$ Mestranda em Estudos Linguísticos pela Universidade Federal da Fronteira Sul (UFFS), campus Chapecó-SC. Bolsista Capes.
} 
meanings that would be affiliated to the left of the Brazilian political spectrum, against which the governing subject is opposed.

Keywords: Bolsonaro Government. Coronavirus. Ideological bias. Antiglobalism. Governmentality. Presidential Discourse. 


\section{Considerações iniciais}

Desde o início do ano de 2020, o Brasil enfrenta uma pandemia com graves consequências para a população. Enquanto se está à espera da vacina eficaz que devolva a rotina anterior à pandemia, a COVID-19 suscita cuidados especiais em relação à saúde nos mais diversos afazeres da vida moderna. A atualidade é marcada por inquietação em relação ao aumento da transmissão do vírus, por adequações na interação pessoal entre os indivíduos para evitar o contágio e por internações hospitalares e óbitos em número ascendente. Diante desse cenário, espera-se que Prefeitos, Governadores e o Presidente da República determinem procedimentos coletivos e regras de conduta para o bem-estar geral da população, a partir do resultado de pesquisas científicas em andamento em vários países e de diretrizes aconselhadas por profissionais da área médica e por organismos internacionais.

De acordo com Vilela, repórter da Agência Brasil (2020), em junho deste ano, Jair Messias Bolsonaro, atual presidente do Brasil, posicionou-se criticamente em relação à atuação da Organização Mundial da Saúde, a OMS, quanto ao combate à COVID-19. Segundo o presidente, a organização trabalharia com viés ideológico e, por isso, o Brasil não seria, supostamente, conivente com as decisões da Organização. Não obstante, Bolsonaro, ao considerar uma possível saída do país da Organização, seguiria o exemplo dos Estados Unidos, pois Donald Trump anunciou a saída norte-americana da OMS em plena pandemia, conforme poderá ser observado adiante, nas sequências discursivas que selecionamos para o corpus de análise.

A citação sobre as práticas políticas dos Estados Unidos, bem como o apontamento de um viés ideológico associado ao espectro político da esquerda, é recorrente em discursos do atual governo. Nos discursos da transição para o governo Bolsonaro (2018/2019), a manifestação contra o suposto viés ideológico também é discursivizada e é relacionada a temas e campos sociais diversos, a exemplo da relação à teoria de gênero, às práticas pedagógicas em escolas e às relações internacionais.

Assim, a fala do sujeito presidente apresenta a marca discursiva do viés ideológico também associada à atuação da OMS, com decisões que, na visão do governo, seriam prejudiciais à autonomia do Estado brasileiro no combate à pandemia. A autonomia da nação passa então a ser defendida a partir de um posicionamento supostamente anti-ideológico no campo da saúde, uma das áreas básicas de necessidade da população.

Na ocasião da entrevista na Portaria do Palácio da Alvorada, em 5 de junho de 2020, Bolsonaro indica um modo de governar as relações com o exterior ao afirmar que "não 
precisamos de ninguém de lá de fora para dar palpite na saúde aqui dentro". A nosso ver, esse discurso que evidencia um modo de conceber as relações do Brasil com o exterior, sejam países ou organizações mundiais, organiza-se em torno de um posicionamento antiglobalista, no qual a OMS e a ONU aparecem como ameaças à soberania e à identidade pensada para a nação. Com efeito, o antiglobalismo e o viés ideológico são discursividades imbricadas, visto que o viés ideológico estaria presente em supostas práticas globalistas.

Considerando esse contexto, este artigo tem como objetivo examinar como se produzem os efeitos de sentido relacionados à composição viés ideológico nos discursos do governo Bolsonaro durante a pandemia de COVID-19. Buscamos compreender como a discursividade antiglobalista se materializa nas falas do presidente e do ministro das relações exteriores, Ernesto Henrique Fraga Araújo, imprimindo ao viés ideológico sentidos que seriam filiados à esquerda do espectro político brasileiro, contra os quais os sujeitos governantes se opõem.

Visando atender ao objetivo estabelecido, o artigo está dividido em quatro partes. $\mathrm{Na}$ primeira, discorremos sobre algumas concepções de ideologia que circulam no campo dos estudos discursivos, na tentativa de mostrarmos que o conceito de ideologia é polissêmico e, portanto, difícil de ser definido a partir de uma só vertente. Na segunda seção, apresentamos e discutimos brevemente sobre a metodologia utilizada nesta pesquisa. Em seguida, analisamos recortes do discurso bolsonarista sobre o viés ideológico, em diálogo com conceitos-chave da ancoragem teórico-metodológica. Na seção final, analisamos os discursos bolsonaristas implicados no atual estado de pandemia e as críticas à OMS.

\section{A noção de ideologia nos estudos discursivos}

As concepções que formam o campo das definições de "ideologia" são inúmeras, assim como a história e a memória ligadas ao termo. De acordo com Eagleton (1997), não existe uma única teoria ou acordo a respeito do significado e do uso da palavra ideologia. Os movimentos de sentido mobilizados pelo termo, na maioria das vezes, não são observados pelo sujeito que os (re)produzem. Para compreender melhor o emprego do discurso da e sobre a ideologia na AD, investigamos os estudos de Pêcheux (2014), Orlandi (2015) e Foucault (2014a; 2015; 2018a) sobre o tema.

Considerado como um dos fundadores da $\mathrm{AD}$ francesa, Pêcheux constrói seus pressupostos teóricos sob três pilares: materialismo histórico, linguística e psicanálise. Com 
relação ao primeiro, o autor francês faz uma releitura e se apropria de diversos conceitos elaborados por Althusser (1985). Desse modo, busca compreender as condições ideológicas de reprodução e transformação de produção, entendendo que "todo processo discursivo se inscreve numa relação ideológica de classes" (PÊCHEUX, 2014, p. 82). Ao desenvolver a noção de formação ideológica (atitudes e representações que se relacionam com posições de classe), Pêcheux (2014) compreende que as formações ideológicas comportam formações discursivas, sendo que a última é "aquilo que, numa formação ideológica dada [...] determina o que pode e deve ser dito" (PÊCHEUX, 2014, p. 147). Logo, os discursos são ideológicos e há ideologia para e pelo sujeito.

Nesse sentido, para a AD de vertente pêcheutiana, a ideologia é item constituinte dos discursos, ou seja, não há discursividade possível sem a interpelação ideológica. Orlandi (2015) relaciona a ideologia e o sujeito nos estudos discursivos indicando que o próprio ato de interpretação pelo sujeito já atesta a presença da ideologia, porque esta é condição para a constituição do sujeito e dos sentidos. O indivíduo constitui-se sujeito para produzir o seu dizer, logo, “[...] não há discurso sem sujeito. E não há sujeito sem ideologia” (ORLANDI, 2015, p. 45). O efeito da relação do sujeito com a língua e com a história resulta num funcionamento imaginário. As imagens permitem que as palavras se relacionem às coisas, e se o sujeito não sofrer os efeitos do simbólico, ele não se constitui e não produz sentidos. Portanto, na passagem do indivíduo para o sujeito, que é o enunciador do discurso, a ideologia está presente.

Um autor que exerce grande influência nos estudos discursivos é Michel Foucault. Contudo, no decorrer das obras de Foucault (2014a; 2015; 2018a), identificamos a recusa de análises no campo da ideologia, assim como o conjunto de noções normalmente associadas, como alienação, falsa consciência, mistificação, entre outros. Em A sociedade punitiva, Foucault (2015) rejeita o esquema teórico da ideologia ao defender que o poder não pode ser reduzido à dicotomia: violência ou ideologia. Todavia, entende que o poder ocorre num lugar de formação de saber. Já no primeiro capítulo de Microfísica do poder (FOUCAULT, 2018a), são elencados três motivos pelos quais o autor considera improvável a utilização da noção de ideologia em suas pesquisas.

A primeira é que queira-se ou não, ela está sempre em oposição virtual a alguma coisa que seria a verdade. Ora, creio que o problema não é de se fazer a partilha entre o que num discurso releva da cientificidade e da verdade e o que revelaria de outra coisa; mas de ver historicamente como se produzem efeitos de verdade no interior de discursos que não são em si nem verdadeiros, nem falsos. Segundo inconveniente: refere-se necessariamente a alguma coisa como o sujeito. Enfim, a 
ideologia está em posição secundária com relação a alguma coisa que deve funcionar para ela como infraestrutura ou determinação econômica, material, etc. (FOUCAULT, 2018a, p. 44).

A partir do primeiro motivo, Foucault (2018a) deixa clara sua visão sobre o que é ideologia, ou seja, algo que está em oposição à verdade e, portanto, não é útil, visto que busca entender como são produzidos os efeitos de verdade dos discursos. O autor aponta que o interesse não é em definir num discurso o que há de científico e de verdadeiro e revelar algo outro, mas entender como, historicamente, os efeitos de verdade se articulam nos discursos. $\mathrm{O}$ segundo motivo seria a vinculação da ideologia com alguma coisa que represente o sujeito, mas não o sujeito em si. E o terceiro motivo diz respeito à condição secundária da ideologia com relação a alguma realidade, estrutura, mundo material, ou seja, a ideologia precisa de uma infraestrutura para funcionar.

Desse modo, o autor propõe a análise da relação entre verdade e poder, e não entre ciência e ideologia (FOUCAULT, 2018a). Assim, a verdade é o próprio poder e este ocorre sobre o corpo dos sujeitos e não pelo plano da consciência. Isso posto, na obra Do governo dos vivos, Foucault (2014a) desenvolve a noção de Anarqueologia, a qual consiste em recusar a delimitação de grupos universais, não assumir um posicionamento humanista, analisar os mecanismos de poder de modo tecnológico e formar agenciamentos de resistência. Nesse sentido, esse novo dispositivo de análise proposto por Foucault (2014a) permite investigar as diferentes formas de dominação e de assujeitamento, não como uma distorção da verdade imposta pela ideologia, mas no sentido de dominação por intermédio de um poder da verdade.

A partir das discussões realizadas até aqui, destacamos que na área da $\mathrm{AD}$ há diferentes posicionamentos teóricos e metodológicos a respeito do estudo do campo ideológico. Reforçamos que concepções são estudadas, rearranjadas e transformadas a partir da influência das mudanças ocorridas nas sociedades. Portanto, o campo ideológico comporta conceitos que são discutidos, criticados, reformulados e adaptados, seja para tentativas de compreensão do funcionamento da sociedade ou para discussões e mecanismos de ataque no campo político.

Quando Bolsonaro aborda o tema da ideologia, ele (re)produz enunciados e se sujeita à língua, à história e à própria ideologia, esta última de acordo com o entendimento dado pelos estudos do discurso: ideologia entendida como processo de determinação histórico-social de sujeitos e de sentidos. Ao tomar a fala, o governante anuncia que "ideologia" quem tem são os outros, os adversários políticos. "Ideologia", na fala do governante, distancia-se, portanto, da noção de ideologia tal como a concebe a AD. No caso do discurso de Bolsonaro, o termo 
"ideologia" requisita sentidos negativos, ligados à esquerda e ao globalismo, conforme discutiremos adiante.

\section{As condições do olhar da Análise de Discurso}

Com a intenção de atender ao objetivo estabelecido, este artigo tem orientação teóricometodológica ancorada na Análise de Discurso (AD) ligada à escola franco-brasileira. Desse modo, aplicam-se alguns conceitos-chave para análise: ideologia, memória, formação discursiva e governamentalidade, os quais serão discutidos no decorrer do artigo. Na análise discursiva buscamos entender o enunciado na sua singularidade, nas suas condições de existência, nos seus limites, nas suas relações com outros discursos e o que esse enunciado elimina. Partimos da noção foucaultiana sobre discurso, na qual discurso é "conjunto de enunciados que se apoia em um mesmo sistema de formação" (FOUCAULT, 2017, p. 131). Esse sistema de formação é entendido como formação discursiva, no qual é possível descrever sistemas de dispersão em certo número de enunciados.

No campo dos estudos discursivos trabalhamos com a seleção de um corpus, para focalizar os objetivos de pesquisa. Nesta linha, selecionamos para este artigo sequências discursivas dos pronunciamentos do presidente Bolsonaro e do ministro das relações exteriores para compor o material de análise. Além disso, a abordagem e a discussão dos conceitos-chave e dos recortes do corpus acontecem a partir de um movimento metodológico constante, denominado por Petri (2013) como movimento pendular: "a metodologia da Análise de Discurso existe, mas não para, está em suspenso, em movimento, (de)pendendo como o pêndulo, relativizando os olhares sobre o mesmo objeto" (PETRI, 2013, p. 41-42).

\section{O "viés ideológico" como regularidade discursiva}

A regularidade do viés ideológico surgiu com ênfase nos discursos bolsonaristas na transição para o governo do presidente Bolsonaro, entre 2018 e 2019, conforme apresenta Agnoletto (2020). Além do presidente, o ministro das relações exteriores, Ernesto Araújo, também proferiu discursos oficiais que trataram do "viés" em questão. Podemos indicar como marco zero do discurso sobre o viés ideológico a confirmação da eleição de Bolsonaro. Efetuamos essa marcação temporal para notabilizar um recorte que considera a discursividade 
Eric Duarte Ferreira; Ana Cristina Agnoletto; Maruana Kássia Tischer Seraglio. O discurso bolsonarista sobre o viés ideológico na pandemia da COVID-19.

desse governo. Cabe indicar que a $\mathrm{AD}$ permite-nos refletir sobre os já-ditos, logo, destaca-se a noção de memória discursiva na reflexão sobre os sentidos que emanam das escolhas de fala dos sujeitos.

Em um dos discursos da vitória do presidente, transmitido pela rede social Facebook, em 28 de outubro de 2018, Bolsonaro citou uma relação amistosa com o presidente dos Estados Unidos e o intento de empregar no Ministério das Relações Exteriores (MRE) um ministro que acolha os interesses almejados para as relações exteriores, conforme a Sequência Discursiva 1 (SD1), a seguir:

SD1 - Acabei de receber ligação de alguns líderes, entre eles o presidente dos Estados Unidos acabou de nos ligar, nos desejou boa sorte e obviamente foi um contato bastante amigável, e nós queremos sim nos aproximar de vários países do mundo, sem o viés ideológico, por isso, a necessidade de termos um bom ministro das relações exteriores, que converse com o mundo todo, pensando, então, num projeto de o Brasil fazer comércio, logicamente sem prejudicar o nosso, o nosso empresário, o nosso industrial aqui no Brasil, buscando então parcerias com esses países, de modo que a nossa economia comece realmente a andar (BOLSONARO, 2018a, n.p., grifos nossos).

A discursividade do viés ideológico, em outubro de 2018, está associada a práticas de outros países que, segundo Bolsonaro, devem ser banidas. Considerando que os discursos remetem-se a outros, pela acepção do já-dito na $\mathrm{AD}$, traremos à reflexão discursos do ministro das relações exteriores e do presidente Donald Trump de outro período, um tempo-espaço anterior. Foucault (2017), em A Arqueologia do Saber, esclarece-nos que os enunciados estão abertos a repetições, a transformações e a reativações, ou seja, relacionam-se aos enunciados que os precedem e aos que os seguem. Nesse sentido, quando Donald Trump discursa em Varsóvia, na Polônia, em 2017, sobre a semelhança das ações dos Estados Unidos e da Polônia para a manutenção de suas culturas, e quando Araújo escreve um ensaio neste mesmo ano enaltecendo o posicionamento nacionalista de Trump e evoca uma recuperação do patriotismo no Brasil, observamos um entrelaçamento discursivo apresentado numa rede de memórias.

Para Courtine (2016, p. 26), um dos procedimentos de estudo da AD está ancorado na investigação da memória, pois é " [...] a partir do domínio da memória que será caracterizada a formação dos enunciados e que serão analisados os efeitos que produz, dentro de um processo discursivo [...]". No ensaio produzido para os Cadernos do Instituto de Pesquisas de Relações Internacionais (IPRI), em 2017, Araújo faz referência a Trump como o presidente que poderia "salvar" o Ocidente, possibilitando a preservação dos valores tradicionais, da cultura e dos heróis, e combatendo o globalismo. O posicionamento antiglobalista de Araújo no ensaio 
também é percebido, e com ainda mais ênfase, em seu discurso de posse no Ministério das Relações Exteriores, em 2 de janeiro de 2019. Ao identificar o globalismo como um movimento mundial inimigo das nações, o ministro declara que a atuação globalista é contrária à ideia de nação e se constitui por ramificações ideológicas. Logo, o globalismo estaria presente no mundo com uma suposta ideologia que visa a destruição do que se apresenta como positivo para a ideia de unicidade de um País, caracterizada por uma aparente hegemonia cultural.

Cabe destacar, com base nos estudos de Davallon (1999), que um acontecimento sai da indiferença e deixa de ser insignificante quando passa ao nível da memória coletiva. Nesse sentido, observa-se que parte do discurso de Trump (2017) sobre supostas práticas nefastas em nível mundial é recordado no ensaio de Araújo (2017). Esse ensaio ressoa no discurso da sua posse no MRE e também em pronunciamentos de Bolsonaro, tanto à época de sua eleição e da posterior posse no cargo presidencial quanto durante a pandemia de COVID-19.

Conforme Pêcheux (1999), a memória não está num repositório homogeneizado, pois há deslocamentos, contradiscursos, conflitos, dentre outros elementos transformadores. Portanto, compreendemos que não se utilizam as mesmas palavras ou as mesmas construções sintáticas necessariamente. A memória apresenta-se por pistas, posicionamentos, imagens, metáforas utilizadas, estilos, temas, entre outros elementos escolhidos pelos sujeitos dos discursos inseridos num determinado tempo-espaço. Então, os objetos são atingidos por memória, mas têm seus traços atualizados. E no conjunto de efeitos produzidos pela memória, abrimos espaço para compreender a formação discursiva, outro conceito-chave da AD.

\section{Uma leitura da Formação Discursiva Bolsonarista (FDB)}

$\mathrm{Na}$ análise discursiva, investigamos o enunciado na sua singularidade, nas suas condições de produção, nos seus limites e nas relações com outros discursos. Desse modo, além de sua existência na memória, o enunciado também está ligado à articulação e à escrita da palavra, está conectado a enunciados anteriores e posteriores. Foucault (2017) propõe a descrição de sistemas de dispersão quando,

No caso em que se puder descrever, entre um certo número de enunciados, semelhante sistema de dispersão, e no caso em que entre os objetos, os tipos de enunciados, os conceitos, as escolhas temáticas, se puder definir uma regularidade (uma ordem, correlações, posições e funcionamentos, transformações), diremos, 
por convenção, que se trata de uma formação discursiva (FOUCAULT, 2017, p. 47, itálicos do autor).

Uma formação discursiva (FD) não tem contornos definidos, ela é atravessada tanto por objetos instáveis quanto por categorizações. Logo, é importante pensar em uma estratégia de mapeamento da FD observando as regularidades. Em suma, a FD diz respeito ao modo como o discurso é dito e se constrói por meio de relações que se conectam para produzir sentidos para os sujeitos envolvidos, resultando num imaginário coletivo.

A regularidade associada ao combate do viés ideológico, no caso dos discursos bolsonaristas de transição, se relacionam à defesa do antiglobalismo, da promoção da manutenção de valores tradicionais e da religião cristã, à defesa da cultura nacional, ao patriotismo e ao entusiasmo em relação às práticas políticas do presidente dos EUA, Donald Trump. Cabe destacar que o posicionamento do governo em relação à esquerda do espectro político também é apropriado para ser considerado como regularidade, a exemplo de dizer que a população não poderia mais continuar flertando "com comunismo, populismo e extremismo da esquerda" (BOLSONARO, 2018b, n.p.). Em suma, o presidente apresenta um posicionamento que refuta forças que estariam contra os interesses do governo, em discursos que referenciam opositores, como a esquerda, o globalismo e a própria ideologia, no sentido em que ela é determinada nos discursos do sujeito governante.

Os elementos apresentados no parágrafo anterior partem de um gesto de leitura dos discursos, mas não se esgotam. Como estratégia para o reconhecimento da composição da Formação Discursiva Bolsonarista (FDB), estabelecemos relações entre os enunciados que, conforme Foucault (2017), surgem de forma positiva/produtiva para a emergência de objetos discursivos. Assim, elencamos dois objetos de discurso que consideramos fundamentais para refletir o posicionamento bolsonarista nesta pandemia: ideologia e antiglobalismo.

\section{Em que está a ideologia?}

No discurso de posse do presidente Bolsonaro, em $1^{\circ}$ de janeiro de 2019, no Congresso Nacional em Brasília, identificamos alusões constantes ao campo ideológico. Observamos elementos que contribuem para a constituição do viés ideológico como um status quo contra o qual é necessário se erguer para libertar o povo brasileiro. Além disso, o 
Eric Duarte Ferreira; Ana Cristina Agnoletto; Maruana Kássia Tischer Seraglio. O discurso bolsonarista sobre o viés ideológico na pandemia da COVID-19.

pronunciamento do presidente dialoga com elementos do campo religioso. $\mathrm{Na}$ SD2, identificamos a defesa de concepções vistas como tradicionais, como a família e a religião:

SD2 - Vamos unir o povo, valorizar a família, respeitar as religiões e nossa tradição judaicocristã, combater a ideologia de gênero, conservando nossos valores. O Brasil voltará a ser um País livre das amarras ideológicas (BRASIL, 2019a, n.p, grifos nossos).

O combate aos valores que não se encaixam naqueles elegidos pelo presidente Bolsonaro é mencionado. Todavia, este dizer produz um ponto de deriva, se pensarmos a partir do que Pêcheux (2015, p. 53) aborda: "todo enunciado, toda sequência de enunciados é, pois, linguisticamente descritível como uma série (léxico-sintaticamente determinada) de pontos de deriva possíveis, oferecendo lugar a interpretação”. O ponto de deriva na SD2 é caracterizado pela falta de qualificação específica dos valores a serem conservados, bem como das configurações de família. O respeito às religiões (em sentido plural) é mencionado, mas ocorre ênfase na tradição judaico-cristã, o que, de certo modo, coloca as outras em um espaço periférico.

Ademais, ocorre deslize de sentidos ao se optar pela substituição de "teoria de gênero", ligada ao campo acadêmico, para "ideologia de gênero". Neste recorte, a ideologia faz referência a um espaço muito específico, o qual envolve os debates sobre gênero. Além disso, parece estar interligada às amarras ideológicas que devem ser combatidas pelo povo e pelo Estado. Nesse sentido, a troca de "teoria" por "ideologia" aponta para a rejeição de teoria, pois nesse discurso bolsonarista nega-se a legitimidade das ciências humanas ou de grande parte delas. Guimarães (2020) defende que a utilização de gênero como uma categoria de análise consiste na rejeição de conceitos fixos, além de que a confusão entre teoria e ideologia de gênero corresponde, principalmente, à relação do segundo termo com valores de moralidade e de família. Assim,

A 'ideologia de gênero' tornou-se receptáculo e transmissora de variadas concepções reacionárias, que utilizam a retórica dos valores morais em nome do combate a qualquer forma de reivindicação dos direitos das mulheres e dos sujeitos cuja orientação sexual e identidade de gênero desafiem a heteronormatividade estabelecida (GUIMAR ÃES, 2020, p. 12).

Logo, o entendimento precipitado e errôneo da teoria de gênero foi deslocado para ideologia de gênero, iniciando uma campanha contra essa forma de compreender a sexualidade humana, a qual foi tratada como ideologia. A autora esclarece que a adjetivação de "ideologia" corresponde ao significado que Napoleão utilizou, atacando os intelectuais que 
Eric Duarte Ferreira; Ana Cristina Agnoletto; Maruana Kássia Tischer Seraglio. O discurso bolsonarista sobre o viés ideológico na pandemia da COVID-19.

eram contra sua forma de governamentalidade. Assim, "empregam o conceito de ideologia como sinônimo de mentira, falseamento ou manipulação da realidade, no qual o critério de averiguação consiste unicamente na [...] alegação de que o discurso do outro é ideológico porque é contrário ao seu" (GUIMARÃES, 2020, p. 17).

Ademais, verificamos na SD2 um novo ponto de deriva ao ser mencionado que o Brasil voltaria a ser livre. Não sabemos ao certo em qual momento do passado o país foi livre das amarras ideológicas, ou, ainda, durante qual período o país esteve preso às amarras ideológicas. A partir de análises dos discursos do presidente, conforme veremos a seguir, podemos identificar que Bolsonaro avalia que os mandatos dos partidos considerados de esquerda parecem ser os momentos de maior submissão ideológica.

A alusão ao ambiente familiar, aos valores e às tradições também são mencionadas pelo presidente no discurso de posse durante cerimônia de recebimento da faixa presidencial. A ideologia é caracterizada como nefasta, a qual divide a nação brasileira e destrói os ideais defendidos pelo governo Bolsonaro.

SD3 - Não podemos deixar que ideologias nefastas venham a dividir os brasileiros. Ideologias que destroem nossos valores e tradições, destroem nossas famílias, alicerce da nossa sociedade (BRASIL, 2019b, n.p, grifos nossos).

$\mathrm{Na}$ SD3, o presidente sinaliza ser preciso romper com práticas ideológicas nefastas, as quais, na percepção bolsonarista, teriam levado o país a um momento de crise, envolvendo, principalmente, a ética e a moral, aludindo aos valores tradicionais a serem defendidos. Assim como na SD2, aqui a metáfora de guerra estrutura a composição dos enunciados, na forma de uma convocação para a luta contra a destruição e a divisão.

Ao investigarem sobre as metáforas do cotidiano, Lakoff e Johnson (2002) afirmam que a metáfora permeia a linguagem, o pensamento e as ações dos sujeitos. Os autores discutem sobre a metáfora de guerra (discussão é guerra), pois a linguagem cotidiana é carregada de expressões que fazem alusão a esse campo. Nesse sentido, "embora não haja batalha física há uma batalha verbal, que se reflete na estrutura de uma discussão - ataque, defesa, contra-ataque, etc." (LAKOFF; JOHNSON, 2002, p. 47). Olhando para os dois recortes de pronunciamentos do presidente (SD2 e SD3), identificamos elementos como destruir e combater (BRASIL, 2019a), que evidenciam a presença da metáfora de guerra e assim estabelecem relação com a biografia do sujeito presidente, o qual se apresenta como alguém ligado ao militarismo. Assim, a ideologia é escolhida como inimiga do povo brasileiro, justificando futuras ações políticas, econômicas e sociais por parte do governo. 

sobre o viés ideológico na pandemia da COVID-19.

Ao nos deslocarmos para as discussões sobre uma suposta "ideologia de gênero" no âmbito educacional, Guimarães (2020) afirma que, no Brasil, a circulação de "ideologia de gênero" passou a ser maior quando vinculada aos projetos do movimento político Escola sem Partido ${ }^{4}$. Assim, a ideologia de gênero seria uma ideologia "antifamília", pois estaria ligada aos estudos sobre a homossexualidade. A autora enfatiza que durante a campanha eleitoral de Bolsonaro, havia palavras de ordem contra a suposta doutrinação da ideologia de gênero "sem qualquer base empírica ou fundamento científico" (GUIMARÃES, 2020, p. 18), desqualificando as disciplinas correspondentes aos estudos de gênero. Na SD4, a seguir, observamos a presença da ideologia novamente em sentido negativo e com relação às crianças.

SD4 - Temos o grande desafio de enfrentar os efeitos da crise econômica, do desemprego recorde, da ideologização de nossas crianças, do desvirtuamento dos direitos humanos e da desconstrução da família (BRASIL, 2019b, n.p, grifos nossos).

O discurso da denominada "ideologização de crianças" também está presente no pronunciamento de membros do governo bolsonarista, principalmente ligados ao campo educacional e familiar. Ricardo Vélez Rodríguez, ao tomar posse como ministro da educação em 2019, afirmou que "à agressiva promoção da ideologia de gênero somou-se a tentativa de derrubar as nossas mais caras tradições pátrias" (RODRÍGUEZ, 2019, n.p). Logo, os discursos que circulam na formação discursiva bolsonarista dizem respeito a uma suposta doutrinação que discutiria sobre aspectos de gênero.

A ideologização das crianças e o desvirtuamento dos direitos humanos podem ser entendidos na esteira dos sentidos construídos para a compreensão do objeto de discurso denominado como "marxismo cultural". O então ministro da educação inclusive menciona literalmente a expressão, ao final de seu discurso de posse:

Combateremos com denodo o marxismo cultural hoje presente em instituições de educação básica e superior. Trata-se de uma ideologia materialista, alheia aos nossos mais caros valores de patriotismo e de visão religiosa do mundo (RODRÍGUEZ, 2019, n.p).

\footnotetext{
${ }^{4} \mathrm{O}$ movimento se apresenta como defensor do combate ao que ele considera doutrinação de esquerda nas escolas brasileiras. No site do movimento, encontramos o seguinte: "O que é o Programa Escola sem Partido? Programa Escola sem Partido é um conjunto de medidas previsto num anteprojeto de lei elaborado pelo Movimento Escola sem Partido, que tem por objetivo inibir a prática da doutrinação política e ideológica em sala de aula e a usurpação do direito dos pais dos alunos sobre a educação moral dos seus filhos" (Disponível em: <http://escolasempartido.org/>. Acesso em: 26 jan. 2021).
} 
As críticas ao marxismo nas escolas passam pelo entendimento de que, ao serem discutidos assuntos relacionados a gênero ou à política nas escolas, muitos alunos seriam doutrinados ideologicamente. O presidente, inclusive, durante cerimônia de posse de Abraham Weintraub, substituto de Ricardo Vélez Rodríguez, enfatiza que: "nós queremos uma garotada que comece a não se interessar por política, como é atualmente, dentro das escolas, não é?" (BRASIL, 2019c, n.p). Assim, a escola não é entendida como ambiente para discussões que desperte o interesse dos estudantes por política.

Nesse contexto, também observamos algumas falas da Ministra Damares Regina Alves, atuante no Ministério da Mulher, Família e Direitos Humanos. Em janeiro de 2019, conforme reportagem de Cerioni (2019), da revista Exame, Damares orienta alguns hábitos e princípios para a população brasileira: "menino veste azul e menina veste rosa" e "menina será princesa e menino será príncipe". Com efeito, observam-se relações com o ataque à teoria de gênero, que é identificada como ideologia de gênero no governo Bolsonaro. Esta espécie de aconselhamento sobre as cores que os meninos e as meninas devem usar em suas vestimentas apoia-se na tradição e no conservadorismo reacionários. É possível, conforme percepções relatadas por Agnoletto (2020), articular um prolongamento da incidência dessas falas na educação, pois o discurso pedagógico cumpre uma parte significativa na formação pessoal e profissional do aluno que frequenta a escola desde a tenra idade. Desse modo, o pronunciamento de Damares impacta no domínio discursivo pedagógico no que tange à transmissão e à recepção de sentidos sobre a importância da tradição e dos elementos culturalmente formados no imaginário da população, especialmente para a formação das crianças.

O viés ideológico como regularidade no discurso bolsonarista aponta o "marxismo cultural" não apenas em âmbito nacional, como supõe o combate ao globalismo. Abordaremos a relação entre ideologia e globalismo na seção seguinte, com vistas a discutir como a discursividade antiglobalista se materializa na fala do presidente, imprimindo ao viés ideológico sentidos que seriam filiados à esquerda do espectro político brasileiro, contra os quais o sujeito governante se opõe.

\section{Na esteira do posicionamento antiglobalista bolsonarista}

No governo Bolsonaro, conforme exposto na dissertação Discursos antiglobalistas durante o período de transição para o governo Bolsonaro (2018/2019), de Agnoletto (2020), 
Eric Duarte Ferreira; Ana Cristina Agnoletto; Maruana Kássia Tischer Seraglio. O discurso bolsonarista sobre o viés ideológico na pandemia da COVID-19.

o antiglobalismo assume a existência de um movimento mundial indesejável gerenciado por administradores que seriam inacessíveis à população em geral, e que trabalharia numa perspectiva de governança global impondo determinados padrões com uma consequente inoperância da soberania nacional.

Na luta pela afirmação da existência desse suposto movimento globalista ideológico, com transversalidade no processo da globalização no que refere aos avanços tecnológicos e maior integração entre os países, os discursos antiglobalistas apresentam a identificação de uma determinada manipulação do pensamento da população. Pelas palavras de Paulo de Oliveira Eneas, brasileiro, analista político e escritor de Geopolítica Contemporânea: desconstrução de narrativas da esquerda globalista (2017), a manipulação do pensamento da população se construiria na transmissão do "politicamente correto" e na "falácia do multiculturalismo".

Cabe destacar, conforme Foucault (1996, p. 10), que "[...] o discurso não é simplesmente aquilo que traduz as lutas ou os sistemas de dominação, mas aquilo por que, pelo que se luta, o poder do qual nos queremos apoderar." (FOUCAULT, 1996, p. 10). Nesse sentido, compreendemos que, na ordem arriscada a que os sujeitos se submetem no discurso e impelidos pelas instituições à manifestação, o governante disputa o que considera ser uma hegemonia da narrativa de esquerda na sociedade, nas escolas e na mídia, e apresenta argumentos e elementos persuasivos para que o que é dito obtenha êxito e aceitação. Aspectos retóricos, presentes nos enunciados, fazem parte do estilo empregado dentro de uma determinada formação discursiva e favorecem a identificação das estratégias e filiações empregadas nos pronunciamentos.

Ao identificar-se no espectro político de direita, o governo Bolsonaro se apresenta também como partidário do liberalismo na área econômica. As relações internacionais são tratadas de um modo específico, que buscaria banir a suposta ideologia e assegurar um conservadorismo de costumes. Refutando as práticas políticas anteriores, ou seja, do governo de esquerda, representado, especialmente, por Dilma e Lula, ex-presidentes do Brasil, Bolsonaro traz a promessa de um novo momento político. Nas sequências discursivas a seguir, podemos observar a colagem da ideologia às relações internacionais.

SD5 - Montamos nossa equipe de forma técnica, sem o tradicional viés político que tornou o Estado ineficiente e corrupto [...]. Precisamos criar um círculo virtuoso para a economia que traga a confiança necessária para permitir abrir nossos mercados para o comércio internacional, estimulando a competição, a produtividade e a eficácia, sem o viés ideológico (BRASIL, 2019a, n.p, grifos nossos). 
Eric Duarte Ferreira; Ana Cristina Agnoletto; Maruana Kássia Tischer Seraglio. O discurso bolsonarista sobre o viés ideológico na pandemia da COVID-19.

SD6 - Vamos retirar o viés ideológico de nossas relações internacionais (BRASIL, 2019b, n.p, grifos nossos).

Com o suposto viés ideológico, o Brasil estaria subordinado a interesses alheios. Pela perspectiva da discursividade do politicamente correto, conforme Eneas (2017), o Brasil estaria em uma posição de aceitação sem precedentes e não ofensa a outras culturas, quer dizer, estaria negando a si mesmo e exaltando as culturas estrangeiras. $\mathrm{O}$ autor brasileiro associa o politicamente correto à atuação da esquerda e, como vimos, Bolsonaro se coloca num posicionamento de desabono da esquerda.

Cabe-nos analisar o propósito para a área econômica no que tange às relações internacionais, com vistas à ligação da área com as relações internacionais, assim como exposto na SD5. Os avanços da globalização, aliados à tecnologia em franco desenvolvimento, têm proporcionado melhor integração e rápida comunicação entre os países. Mas toda essa integração teria uma consequência prejudicial, porque existiriam práticas adjacentes que debilitariam as forças nacionais sob a ótica da existência de um movimento denominado globalismo.

De acordo com Codato, Bolognesi e Roeder (2015), ao considerarmos o contexto latino-americano, o capitalismo como modelo econômico e os preceitos morais tradicionais são elementos presentes na velha direita que são conservados no aparecimento da nova direita. Segundo os autores, essa nova direita enquadra-se em três statements: liberalismo econômico, defesa da democracia e defesa dos valores da família tradicional.

Conforme Foucault (2008), o liberalismo, caracterizado como uma nova arte governamental, articula-se pela fluidez no que diz respeito a

[...] deixar as pessoas fazerem, as coisas passarem, as coisas andarem, laisser-faire, laisser-passer, e laisser-aller, quer dizer essencial e fundamentalmente, fazer de maneira que a realidade se desenvolva e vá, siga seu caminho, de acordo com as leis, os princípios e os mecanismos que são os da realidade mesma (FOUCAULT, 2008, p. 62-63, itálicos do autor).

Conforme a exposição de Foucault, a liberdade está atrelada à faculdade de circulação. As circulações envolvem deslocamentos, trocas e contatos observados pelo soberano, e é atuando sobre o meio que o soberano trabalha na regulação. Considerando-se essa ideia da circulação no escopo do discurso antiglobalista, vemos que este visa mobilizar um impedimento de trocas entre as nações, trocas associadas ao viés ideológico. 
As relações comerciais determinadas como anti-ideológicas e que deveriam estar articuladas ao crescimento da economia no País são apresentadas como solução para os encaminhamentos relativos aos problemas da economia, conforme os pronunciamentos oficiais, os quais associam anti-ideologismo à liberdade. Contudo, seguir o curso pela ótica da existência da liberdade de atuação pode apresentar contradição quando surge a regulação sobre de que modo deve ocorrer o contato com os outros países.

A partir de análises sobre dois modelos teóricos neoliberais, Foucault (2018b) caracteriza ambos por intermédio de uma "fobia ao Estado". O modelo neoliberal alemão é determinado pelas liberdades nos processos econômicos que, por meio do aparato jurídico, delimita a intervenção estatal. Já no neoliberalismo estadunidense são ultrapassadas as barreiras econômicas de mercado, imergindo na vida pessoal e familiar, organizando-a e modelando-a, dando nascimento ao empresário de si mesmo. Como mencionado anteriormente, o liberalismo é caracterizado pela liberdade. Todavia, a vertente neoliberal, essa nova arte governamental, por ser consumidora da liberdade, é também apresentada como gestora desta, pois, além da produção, também realiza o processo de organização e "venda" desta liberdade, ou seja, isso "implica que se estabeleçam limitações, controlos, coerções, obrigações apoiadas em ameaças, etc.” (FOUCAULT, 2018b, p. 94).

Nesse sentido, esse desejo por libertação dos sujeitos inseridos no regime liberal é necessário, pois permite ao governo que regule os comportamentos. No Brasil, como observado em alguns dos recortes do corpus desta pesquisa, Bolsonaro considera a liberdade um princípio fundamental, pois há uma regularidade do desejo em libertar o povo brasileiro das “amarras ideológicas" (BRASIL, 2019a, n.p).

Entretanto, existem perigos que envolvem os sujeitos e que funcionam enquanto equilíbrio das liberdades e instigam o desejo à segurança, pois, de acordo com Foucault (2018b, p. 97), "não há liberalismo sem a cultura do medo". Nesse sentido, a liberdade de propriedade é essencial ao liberalismo e perpassa a liberdade do indivíduo, a qual deve ser protegida por meio da segurança. Assim, o papel do Estado é o de proteger a propriedade privada, visando a manutenção da economia de mercado. Observamos que nos discursos de posse os mecanismos de crítica às noções vinculadas ao viés ideológico funcionam tanto como estímulo à liberdade (no sentido de instigar o povo a desejar a libertação desse viés), como também se relacionam ao medo, pois despertam a vontade de eliminar esse inimigo e promover segurança à população brasileira. Liberdade e medo significam nesse caso desfazerse de amarras ideológicas nefastas esquerdistas, para não ser destruído. 
O antiglobalismo liga-se à ideia da existência de um movimento global que influenciaria, sobretudo, o poder de atuação de um Estado. De acordo com o economista Thorsten Polleit (2017), o globalismo é um conceito da área política e a globalização pertence à área econômica.

O globalismo é uma política internacionalista, implantada por burocratas, que vê o mundo inteiro como uma esfera propícia para sua influência política. O objetivo do globalismo é determinar, dirigir e controlar todas as relações entre os cidadãos de vários continentes por meio de intervenções e decretos autoritários (POLLEIT, 2017, n.p.).

Observando a identificação de um controle mundial, os administradores globalistas valeram-se de práticas manipuladoras em diversas áreas, como na educação, conforme já exposto neste artigo, que pode estender-se à área da saúde. Nesse ponto, causa-nos inquietação parte do discurso de posse do ministro das relações exteriores, Ernesto Henrique Fraga Araújo, em 2 de janeiro de 2019, porque Araújo cita a ONU, conforme verificamos no recorte discursivo selecionado como SD7, a seguir.

SD7 - No sistema multilateral político, especialmente na ONU, vamos reorientar a atuação do Brasil em favor daquilo que é importante para os brasileiros - não do que é importante para as ONGs. Defenderemos a soberania. Defenderemos a liberdade - a liberdade de expressão, a liberdade de crença, a liberdade na internet, a liberdade política (BRASIL, 2019d, n.p. grifos nossos).

Cabe lembrar que a OMS é subordinada à Organização das Nações Unidas (ONU) e coordena questões relativas à emergência de saúde humanitária no mundo ${ }^{5}$. O modo como Araújo convoca uma reorientação da atuação do Brasil perante a ONU implica num questionamento sobre que ações deveriam ser refutadas para a área da saúde. Araújo se insere, assim, na formação discursiva bolsonarista organizada em torno do que é construído como o combate ao viés ideológico.

Paulo Roberto de Almeida, em entrevista à Brasil Paralelo, em 2017, observou que as organizações mundiais podem ser invasivas das soberanias nacionais, no entanto, a própria ONU é garantia aos estados soberanos porque defende os interesses das nações e atua em prol dos direitos humanos, que são de caráter universal. Dessa forma, a ONU tem um papel fundamental no combate a governos que possam ser tiranos. Segundo o diplomata, as maiores violações dos direitos humanos se dariam no âmbito internacional e a ONU e outras

5 Disponível em: <https://www.un.org/en/sections/what-we-do/deliver-humanitarian-aid/index.html〉. Acesso em: 16 dez. 2020. 
organizações precisam atuar na garantia desses direitos. O discurso contra o globalismo, então, se apresenta discursivamente como " [...] uma tentativa de algumas forças conservadoras ou de direita nacionais para rejeitar a sensação de perda de soberania nacional que é feita em prol da globalização" (ALMEIDA, 2017, n.p).

Na próxima seção, realiza-se uma análise estabelecendo relações entre os sentidos determinados para o viés ideológico, que previamente foram abordados neste artigo, e o pronunciamento do presidente Bolsonaro sobre a atuação da OMS no Brasil.

\section{O discurso bolsonarista na pandemia}

No início de junho de 2020, mais precisamente no dia 5, ao conversar com jornalistas na portaria do Palácio da Alvorada, Bolsonaro se pronunciou sobre o trabalho da OMS durante a pandemia de COVID-19. O presidente brasileiro, em seu pronunciamento, fez menção ao rompimento dos Estados Unidos com a OMS. Trump, presidente norte-americano à época, havia informado à imprensa uma semana antes que o relacionamento entre os Estados Unidos e a organização estava encerrado, criticando a atuação desta no período da pandemia e alegando que o grupo era manipulado e servia aos interesses da China (HOLLAND; NICHOLS, 2020). Assim, Bolsonaro, na SD8 e na SD9 a seguir, menciona esse acontecimento e cogita a possibilidade de também romper relações com a OMS.

SD8 - E adianto aqui, os Estados Unidos saíram da OMS, e a gente estuda, no futuro, ou a OMS trabalha sem viés ideológico, ou vamos estar fora também. Não precisamos de ninguém de lá de fora para dar palpite na saúde aqui dentro (BOLSONARO, 2020, n.p, grifos nossos).

SD9 - Para que serve essa OMS? A OMS recomendou há poucos dias não prosseguir mais com os estudos sobre a hidroxicloroquina, e agora voltou atrás. É só tirar a grana deles que eles começam pensar de maneira diferente (BOLSONARO, 2020, n.p, grifos nossos).

O discurso de Bolsonaro, ao mencionar a saída dos EUA da OMS, amplia o escopo do combate ao viés ideológico, colocando-o como uma questão mundial, e não apenas brasileira. A ONU foi criada em 1945 e a OMS foi fundada três anos depois, em 1948, atuando na coordenação de questões relacionadas à saúde de todos os povos. De acordo com o site oficial da ONU, 

sobre o viés ideológico na pandemia da COVID-19.

The World Health Organization (WHO) coordinates the international response to humanitarian health emergencies. WHO is responsible for providing leadership on global health matters, shaping the health research agenda, setting norms and standards, articulating evidence-based policy options, providing technical support to countries and monitoring and assessing health trends. In the 21 st century, health is a shared responsibility, involving equitable access to essential care and collective defense against transnational threats (UNITED NATIONS, [s.d], n.p) ${ }^{6}$.

Como observamos no trecho acima, a OMS atua no mundo a partir da evidência de uma emergência de saúde humanitária. A mídia internacional relata números expressivos da COVID-19 relacionados ao alcance da doença e enfatiza as consequências às pessoas consideradas do grupo risco, como os idosos. Medidas preventivas e diretrizes para o tratamento médico são fundamentais para o freamento da pandemia ${ }^{7}$. Nesse contexto, a organização estabelece padrões e normativas mundiais para o combate à COVID-19.

Nos estudos sobre biopolítica, Foucault (2018b) discute as relações de poder entre o Estado e a população. Nestas relações mediadas pela nova governamentalidade, a vida se constitui como elemento fundamental, desse modo, caberia ao Estado regular a vida dos indivíduos por meio de intervenções. O enunciado "ninguém de lá de fora para dar palpite na saúde aqui dentro" aponta que as ações da OMS debilitariam o seu poder sobre questões que interferem diretamente nas políticas nacionais de governo. Perante a pandemia, os chefes de Estado têm ações que são assistidas e podem ser questionadas internacionalmente. Assim, o presidente brasileiro teria um papel mais reduzido frente às decisões da OMS no que tange à questão epidêmica. Como efeito desse enfraquecimento, Bolsonaro passa a cogitar uma possível saída da organização.

Considerando que, na esteira de pensamento bolsonarista, há práticas globalistas no mundo que podem afetar a vida das pessoas, modelando padrões e comportamentos, compreendemos que um dos efeitos de sentido provocados pelo discurso bolsonarista na SD8 remete-se ao antiglobalismo, marcando um movimento de resistência ao que não está delimitado apenas às fronteiras brasileiras. Ademais, ao questionar a importância e a

\footnotetext{
${ }^{6}$ Tradução livre: "A Organização Mundial da Saúde (OMS) coordena a resposta internacional às emergências de saúde humanitária. A OMS é responsável por fornecer liderança em questões de saúde global, moldar a agenda de pesquisa em saúde, definir normas e padrões, articular opções de políticas baseadas em evidências, fornecer apoio técnico aos países e monitorar e avaliar tendências de saúde. No século 21, a saúde é uma responsabilidade compartilhada, envolvendo o acesso equitativo aos cuidados essenciais e a defesa coletiva contra ameaças transnacionais".

${ }^{7}$ Os números diários da pandemia podem ser consultados na plataforma Google, na internet. No momento desta pesquisa, mais de 74 milhões de pessoas no mundo já contraíram o vírus. Destas, mais de um milhão e meio já faleceram em decorrência da Covid-19. Disponível em: $<$ https://www.google.com/search?q=n\%C3\%BAmeros+d a + covid+19\&oq=n\%C3\%BAmeros+da + covid $+19 \& a q s=$ chrome $.0 .018 .7034 j 0 j 7 \&$ sourceid=chrome \&ie=UTF-8 $>$. Acesso em: 17 dez. 2020.
} 
Eric Duarte Ferreira; Ana Cristina Agnoletto; Maruana Kássia Tischer Seraglio. O discurso bolsonarista sobre o viés ideológico na pandemia da COVID-19.

necessidade da OMS na SD9, Bolsonaro realiza um ataque frontal ao globalismo, em conformidade com o pensamento de Trump sobre a defesa das fronteiras, sejam elas políticas, econômicas, sociais, culturais, entre outros aspectos da ordem do imaginário.

A partir destas discussões, observamos que há indícios de que Bolsonaro considera a OMS ideológica, no sentido que ele assume para "ideologia” (pensamento do adversário político). Assim, na compreensão do presidente, as atitudes da Organização são guiadas pelo que é determinado como viés ideológico, o qual é repudiado pelo governante brasileiro por apresentar traços globalistas e por, na sua visão, debilitar a soberania da nação.

Em abril de 2020, o ministro Araújo escreveu no blog intitulado Metapolítica 17: contra o globalismo, o texto Chegou o comunavírus ${ }^{8}$, atestando que o coronavírus nos faria despertar para o pesadelo comunista. Segundo o ministro,

SD10 - A pretexto da pandemia, o novo comunismo trata de construir um mundo sem nações, sem liberdade, sem espírito, dirigido por uma agência central de "solidariedade" encarregada de vigiar e punir. Um estado de exceção global permanente, transformando o mundo num grande campo de concentração (ARAÚJO, 2020, n.p.).

Araújo, no decorrer do texto, tece críticas à OMS e ao livro "Vírus", do filósofo esloveno Slavoj Žižek. Para o ministro, é preciso combater a ideia de que o coronavírus significaria uma oportunidade de construir uma ordem mundial sem nações e sem liberdade. Ou seja, haveria um jogo comunista-globalista com o intuito de se aproveitar da pandemia para escravizar e controlar o ser humano. Assim, ao mencionar que o comunismo é "dirigido por uma agência central de 'solidariedade'", Araújo dialoga com Bolsonaro ao entender que a OMS extrapola os limites e os poderes das nações.

Segundo Araújo (2020), haveria uma transferência de poder das nações para a OMS com a alegação de que as ações de combate à COVID-19 seriam mais eficientes estando elas centralizadas em um organismo internacional. Contudo, Araújo questiona esta alegação, porque ela jamais teria sido comprovada. Desse modo, este argumento se sustentaria dentro do suposto projeto comunista-globalista e estaria em diálogo com outras organizações globais, como a Organização das Nações Unidas para a Educação, a Ciência e a Cultura (UNESCO).

A expressão "campo de concentração" remete-se ao evento histórico do nazismo, indicando item de memória discursiva e entrelaçamento das concepções de comunismo, nazismo e globalismo, todos "ismos" apresentados como formas governamentais prejudiciais

\footnotetext{
${ }^{8}$ Mesmo não sendo discurso oficial, esse e outros textos presentes no blog do ministro mantêm importantes relações interdiscursivas com seus pronunciamentos oficiais. Texto disponível em: <https://www.metapoliticabrasil.com/post/chegou-o-comunav\%C3\%ADrus>. Acesso em: 17 dez. 2020.
} 
Eric Duarte Ferreira; Ana Cristina Agnoletto; Maruana Kássia Tischer Seraglio. O discurso bolsonarista sobre o viés ideológico na pandemia da COVID-19.

aos governos nacionais. Nesse contexto, refletindo sobre a noção de ponto de deriva de Pêcheux (2015), compreendemos que um dos efeitos de sentido da expressão "campo de concentração" apresenta-se como uma alegoria do ser humano que está desprovido de liberdade, preso a um regime totalitário, sendo vigiado e punido.

Outro efeito de sentido do enunciado "campo de concentração", citado no texto como aprisionamento, faz remissão ao período da quarentena em que as pessoas permanecem o máximo possível em suas casas para evitar o risco de infecção pela COVID-19. Em situações de lockdown, este "campo de concentração" é mais agressivo e o Estado pode instituir ônus financeiro aos que descumprem as regras, evidenciando as noções que Foucault discute em Vigiar e Punir (2014b), livro mencionado pelo ministro no blog Metapolítica 17.

O panóptico, ilustrado por Foucault (2014b), é uma figura arquitetural representativa da vigilância e da punição. Quando Foucault trabalha sobre os sentidos do panóptico, o autor estabelece relações com as enfermidades. Durante o período de quarentena é preciso ter um registro permanente. Tudo é observado e reportado a uma instância maior de poder. Logo, o registro da doença e da morte interfere nas decisões que são tomadas. Nesse sentido, "a ordem responde à peste" (FOUCAULT, 2014b, p. 192), quer dizer, o vigiar e o punir não apresentariam apenas sentidos negativos para o controle da doença. Assim, a partir das consequências ocasionadas pelas doenças, a instituição de poder, ou seja, o próprio poder, atua na manutenção da promoção da vida. Logo, a OMS agiria como uma instância maior de poder que procede no controle da propagação do vírus, a partir de dados.

A metáfora como estilo discursivo está presente no texto de Araújo na expressão "vírus ideológico", ligada à ideia da construção do comunismo no mundo. Podemos estabelecer uma articulação intertextual e interdiscursiva entre "vírus ideológico" e "viés ideológico". O vírus, como doença que amedronta as pessoas, carrega um viés ideológico para, na visão de Araújo, tomar as liberdades das pessoas.

SD11 - O vírus aparece, de fato, como imensa oportunidade para acelerar o projeto globalista. Este já se vinha executando por meio do climatismo ou alarmismo climático, da ideologia de gênero, do dogmatismo politicamente correto, do imigracionismo, do racialismo ou reorganização da sociedade pelo princípio da raça, do antinacionalismo, do cientificismo. São instrumentos eficientes, mas a pandemia, colocando indivíduos e sociedades diante do pânico da morte iminente, representa a exponencialização de todos eles (ARAÚJO, 2020, n.p.).

O ministro Araújo (2020) menciona que alguns instrumentos estariam sendo utilizados para agilizar o denominado projeto globalista, como o climatismo ou alarmismo climático, a ideologia de gênero, o dogmatismo do politicamente correto, o imigracionismo, o 
racionalismo, o antinacionalismo e o cientificismo. As orientações advindas da OMS têm respaldo técnico por meio de avaliações e testes, por isso são inseridas no domínio discursivo científico. Contudo, ao retomarmos a SD9 em que Bolsonaro questiona a utilidade da OMS, "pra que se serve essa OMS?", e as críticas de Araújo à centralização de poderes pela organização, entendemos que tanto o presidente quanto o ministro desabonam o discurso científico que circula na entidade.

\section{Considerações finais}

Em meio à pandemia de COVID-19, é crescente o interesse pelos posicionamentos, falas e condutas apresentadas pelo governante em relação ao enfrentamento da enfermidade. Ao defender um medicamento sem comprovação segura de eficácia (hidroxicloroquina) e ao criticar determinadas diretrizes da OMS, seu discurso produz efeitos semânticos que colam sentidos negativos de esquerdismo à marca viés ideológico. Verificamos que há três campos em que o viés ideológico surge de modo regular: no da educação crítica, no da teoria de gênero e no do globalismo, todos concebidos como esquerdismos contra os quais seria preciso lutar para não haver viés.

Por meio das análises da fala do presidente sobre as ações da OMS durante a pandemia, examinamos uma ligação entre os discursos de Bolsonaro e de Trump, com relação ao patriotismo e ao antiglobalismo. O presidente brasileiro, na luta contra o que considera ser um viés internacional, assume que a OMS estaria articulada ao espectro político de esquerda, com associação a supostas práticas comunistas, favorecendo um projeto global sem restrição de fronteiras. Além disso, a OMS, ao atuar em questões de combate à Covid-19, provocaria um abrandamento do poder presidencial sobre questões políticas relacionadas à pandemia dentro do país.

$\mathrm{O}$ ataque ao globalismo, a defesa das fronteiras e a refutação aos discursos científicos são elementos observados nas análises dos discursos do governo Bolsonaro durante a pandemia. Os objetos discursivos viés ideológico e antiglobalismo estão imbricados nos pronunciamentos do governo desde a sua transição (2018/2019), sob a perspectiva de combate, ou seja, no intento de derrotar o elemento externo: o comunismo, o globalismo, o esquerdismo, o ideologismo e outros "ismos" supostamente prejudiciais ao desenvolvimento do país. Esses elementos são articulados pelas expressões "comunavírus" e "vírus 
Eric Duarte Ferreira; Ana Cristina Agnoletto; Maruana Kássia Tischer Seraglio. O discurso bolsonarista sobre o viés ideológico na pandemia da COVID-19.

ideológico", apresentadas pelo ministro Araújo, de modo que uma rede de memórias que compõe o discurso bolsonarista se atualize por meio de sentidos ligados a antiesquerdismo.

\section{Referências}

AGNOLETTO, Ana Cristina. Discursos antiglobalistas durante o período de transição para o governo Bolsonaro (2018-2019). 2020. 128f. Dissertação (Mestrado em Estudos Linguísticos) - Programa de Pós-graduação em Estudos Linguísticos, Universidade Federal da Fronteira Sul, Chapecó, Santa Catarina, 2020.

ALTHUSSER, Louis. Aparelhos Ideológicos de Estado: nota sobre os aparelhos ideológicos de Estado (AIE). Tradução Maria Laura V. de Castro. Introdução crítica José Augusto Albuquerque. 2. ed. Rio de Janeiro: Graal, 1985.

ARAÚJO, Ernesto Henrique Fraga. Chegou o comunavírus. Metapolítica 17: contra o globalismo. Blog. 22 abr. 2020. Disponível em: <https://www.metapoliticabrasil.com/post/chegou-o-comunav\%C3\%ADrus>. Acesso em: 17 dez. 2020.

ARAÚJO, Ernesto Henrique Fraga. Trump e o Ocidente. Cadernos de Política Exterior, Instituto de Pesquisa de Relações Internacionais, Brasília, FUNAG, ano 3, n. 6, p. 323-356, dez. 2017, 2017.

ARISTÓTELES. Arte Retórica. 16. ed. Tradução Antônio Pinto de Carvalho. Rio de Janeiro: Ediouro, 1998.

BECHARA, Evanildo. Moderna Gramática Portuguesa. 37. ed. rev., ampl. e atual. conforme o novo Acordo Ortográfico. Rio de Janeiro: Nova Fronteira, 2009.

BOLSONARO, Jair Messias. Um agradecimento a todos pela confiança e apoio! Rio de Janeiro, 28 out. 2018a. Facebook: jairmessias.bolsonaro. Disponível em: <https://www.facebook.com/jairmessias.bolsonaro/videos/2076031999084232/>. Acesso em: 2 jun. 2019.

BOLSONARO, Jair Messias. Veja a íntegra das primeiras falas de Bolsonaro após ser eleito presidente. Folha de São Paulo, São Paulo, 28 out. 2018b. Disponível em: <https://www1.folha.uol.com.br/poder/2018/10/bolsonaro-afirma-em-seu-primeirodiscursoque-tera-governabilidade-leia-integra.shtml>. Acesso em: 2 jun. 2019.

BRASIL. Discurso do Presidente da República, Jair Bolsonaro, durante Cerimônia de Posse no Congresso Nacional. Brasil, 2019a. Disponível em: <https://www.gov.br/planalto/pt-br/acompanhe-o-planalto/discursos/2019/discurso-dopresidente-da-republica-jair-bolsonaro-durante-cerimonia-de-posse-no-congresso-nacional>. Acesso em: 26 nov. 2020.

BRASIL. Discurso do Presidente da República, Jair Bolsonaro, durante cerimônia de Recebimento da Faixa Presidencial. Brasil, 2019b. Disponível em: 
Eric Duarte Ferreira; Ana Cristina Agnoletto; Maruana Kássia Tischer Seraglio. O discurso bolsonarista sobre o viés ideológico na pandemia da COVID-19.

<https://www.gov.br/planalto/pt-br/acompanhe-o-planalto/discursos/2019/discurso-dopresidente-da-republica-jair-bolsonaro-durante-cerimonia-de-recebimento-da-faixapresidencial>. Acesso em: 26 nov. 2020.

BRASIL. Discurso do Presidente da República, Jair Bolsonaro, durante Cerimônia de Posse do Ministro de Estado da Educação, Senhor Abraham Bragança de Vasconcellos Weintraub - Palácio do Planalto. Brasil, 2019c. Disponível em: <https://www.gov.br/planalto/pt-br/acompanhe-o-planalto/discursos/2019/discurso-dopresidente-da-republica-jair-bolsonaro-durante-cerimonia-de-posse-do-ministro-de-estado-daeducacao-senhor-abraham-braganca-de-vasconcellos-weintraub-palacio-do-planalto>. Acesso em: 15 dez. 2020.

BRASIL. Ministério das Relações Exteriores. Discurso do ministro Ernesto Araújo durante cerimônia de posse no Ministério das Relações Exteriores. Brasil, 2019d. Disponível em: <http://www.itamaraty.gov.br/pt-BR/discursos-artigos-e-entrevistascategoria/ministro-das-relacoes-exteriores-discursos/19907-discurso-do-ministro-ernestoaraujo-durante-cerimonia-de-posse-no-ministerio-das-relacoes-exteriores-brasilia-2-dejaneiro-de-2019>. Acesso em: 5 jan. 2019.

BRASIL PARALELO. Globalismo: Bastidores do Mundo | Debate entre Olavo de Carvalho e Paulo R. de Almeida. [S.I.], 13 dez. 2017. Disponível em: <https://www.youtube.com/watch?v=CkgQhnApLow>. Acesso em: 5 out. 2019.

CERIONI, Clara. Menino veste azul e menina veste rosa, diz Damares em vídeo. Exame, São Paulo, 3 jan. 2019. Disponível em: <https://exame.com/brasil/menino-veste-azul-emeninaveste-rosa-diz-damares-em-video/>. Acesso em: 31 jul. 2020.

CODATO, Adriano; BOLOGNESI; Bruno; ROEDER, Karolina Mattos. A nova direita brasileira: uma análise da dinâmica partidária e eleitoral do campo conservador. In: VELASCO E CRUZ, S.; KAYSEL, A.; CODAS, G. (orgs.). Direita, volver! O retorno da direita e o ciclo político brasileiro. São Paulo: Editora Fundação Perseu Abramo, 2015, p. 115-143.

COURTINE, Jean-Jacques. Definição de orientações teóricas e construção de procedimentos em Análise do Discurso. Revista de Estudos do Discurso, Imagem e Som - Policromias, n. 1, v. $\quad$ 1, 2016.20 Disponível <https://revistas.ufrj.br/index.php/policromias/article/view/4090>. Acesso em: 17 set. 2020.

DAVALLON, Jean. A imagem, uma arte de memória? In: ACHARD, P. et al. Papel da Memória. Campinas: Pontes, 1999.

EAGLETON, Terry. Ideologia: uma introdução. São Paulo: Boitempo Editorial, 1997.

ENEAS, Paulo de Oliveira. Geopolítica contemporânea: desconstrução de narrativas da esquerda globalista. São Luís: Livraria Resistência Cultural, 2017.

FOUCAULT, Michel. A Ordem do Discurso. 3. ed. São Paulo: Edições Loyola, 1996.

FOUCAULT, Michel. Segurança, Território e População: curso dado no Collège de France (1977-1978). São Paulo: Martins Fontes, 2008. 
Eric Duarte Ferreira; Ana Cristina Agnoletto; Maruana Kássia Tischer Seraglio. O discurso bolsonarista sobre o viés ideológico na pandemia da COVID-19.

FOUCAUlT, Michel. Do Governo dos Vivos: curso no Collège de France (1979-1980). Tradução Eduardo Brandão. São Paulo: Editora WMF Martins Fontes, 2014a.

FOUCAUlT, Michel. Vigiar e Punir: nascimento da prisão. Tradução Raquel Ramalhete. 42. ed. Petrópolis, RJ: Vozes 2014b.

FOUCAUlT, Michel. A Sociedade Punitiva: curso no Còllege de France (1972-1973). Tradução Ivone Benedetti. São Paulo: Editora WMF; Martins Fontes, 2015.

FOUCAULT, Michel. A Arqueologia do Saber. 8. ed. Rio de Janeiro: Forense Universitária, 2017.

FOUCAUlT, Michel. Microfísica do Poder. Curso no Cóllege de France (1978). 8. ed. Rio de Janeiro/São Paulo: Paz e Terra, 2018a.

FOUCAULT, Michel. Nascimento da Biopolítica. Curso no Collège de France (1978-1979). Com Introdução de Bruno Maçães. Tradução Pedro Elói Duarte. Portugal: Edições 70, 2018b.

GUIMARÃES, Géssica. Teoria de gênero e ideologia de gênero: cenário de uma disputa nos 25 anos da IV Conferência Mundial das Mulheres. Tempo e Argumento, Florianópolis, v. 12, n. 29, e0107, p. 02-27, jan./abr. 2020. Disponível em: < https://revistas.udesc.br/index.php/tempo/article/view/2175180312292020e0107>. Acesso em: 28 nov. 2020. DOI: https://doi.org/10.5965/2175180312292020e0107

HOLLAND, Steve; NICHOLS, Michelle. Trump anuncia rompimento dos Estados Unidos com a OMS. Agência Brasil, Washington, 29 de maio de 2020. Disponível em: $<$ https://agenciabrasil.ebc.com.br/internacional/noticia/2020-05/trump-anuncia-rompimentodos-estados-unidos-com-oms>. Acesso em: 15 dez. 2020.

LAKOFF, George; JOHNSON, Mark. Metáforas da Vida Cotidiana. Campinas: Mercado de Letras, 2002.

ORLANDI, Eni Puccinelli. Análise de Discurso: princípios \& procedimentos. 12. ed. Campinas: Pontes, 2015.

PÊCHEUX, Michel. Papel da memória. In: ACHARD, P. et al. Papel da Memória. Campinas: Pontes, 1999.

PÊCHEUX, Michel. Semântica e Discurso: uma crítica à afirmação do óbvio. Tradução Eni Orlandi et. al. 5. ed. Campinas, SP: Editora da UNICAMP, 2014.

PÊCHEUX, Michel. O Discurso: estrutura ou acontecimento. Tradução Eni Orlandi. 7. ed. Campinas, SP: Pontes, 2015.

PETRI, Verli. O funcionamento do movimento pendular próprio às análises discursivas na construção do 'dispositivo experimental' da análise de discurso. In: PETRI, V.; DIAS, C. (orgs.). Análise de Discurso em Perspectiva: teoria, método e análise. Santa Maria: UFSM, 2013, p. 39-48. 
POLLEIT, Thorsten. A diferença básica entre globalismo e globalização econômica: um é o oposto do outro. Mises Brasil, [S.I.], 1 mar. 2017. Disponível em: <https://www.mises.org.br/Article.aspx?id=2639>. Acesso em: 30 maio. 2019.

RODRÍGUEZ, Ricardo Velez. Discurso de Ricardo Vélez Rodríguez: que mudanças esperar no MEC. Transcrito por Soraia Yoshida. 2019. Disponível em: $<$ https://novaescola.org.br/conteudo/14877/discurso-de-ricardo-velez-rodriguez-quemudancas-esperar-no-mec>. Acesso em: 15 dez. 2020.

TRUMP, Donald. Discurso histórico de Donald Trump na Polônia. [S.I.], 7 jul. 2017. Disponível em: <https://www.youtube.com/watch?v=YnQax8Vcfys>. Acesso em: 9 jul. 2019.

UNITED NATIONS. What we do. [s.d]. Disponível em: 〈https://www.un.org/en/>. Acesso em: 17 dez. 2020.

VILELA, Pedro Rafael. Bolsonaro diz que o Brasil pode sair da OMS. Agência Brasil, Brasília, 5 de junho de 2020. Disponível em: <https://agenciabrasil.ebc.com.br/politica/noticia/2020-06/bolsonaro-diz-que-brasil-pode-sairda-oms>. Acesso em: 25 nov. 2020.

Recebido em: 29 de janeiro de 2021

Aceito em: 22 de março de 2021 